\title{
Development of wear-resistant coatings for automotive parts after processing in SHS conditions
}

\section{Borys Sereda *, Irina Kruglyak* , Dmytro Sereda*, Alex Gaydaenko *, Dmytro Kruglyak **}

* Dniprovsk State Technical University,

2 Dniprobudivska, 51900, Kamyanske, Ukraine

** Zaporizhzhia National University,

66, Zhukovkoho str., 69600, Zaporizhzhia, Ukraine

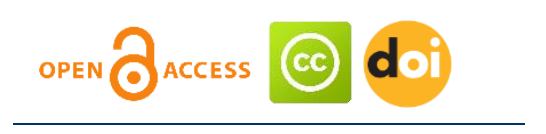

\section{Article history:}

Received:March 9, 2019

1st Revision: March 19, 2019

Accepted: April 28, 2019

\section{DOI:}

10.14254/jsdtl.2019.4-1.3

\begin{abstract}
Methods of obtaining chromium-coated coatings are considered and technology for the formation of boron, silicon and titanium protected layers on steels under conditions of selfpropagating high-temperature synthesis is presented. Using the methods of mathematical modeling, when obtaining wearresistant coatings on machine parts in conditions of selfpropagating high-temperature synthesis, optimal compositions of SHS mixtures have been developed. When tested in sliding friction conditions, the best abrasion resistance, among the coatings under consideration, are chromoaluminium-coated coatings. Their wear resistance is 4.8-5 times higher than in uncoated samples, chromoaluminosilicated and chromoalumotated in 2.1-3.5. The gas-transport method of coating with the help of SHS makes it possible to obtain steel 50 and U8A with increased physical and mechanical properties, without requiring high energy costs and time.
\end{abstract}

Keywords: automotive parts, transport, protective coatings, wear resistance, self propagating high-temperature synthesis, steel.

\section{Introduction}

From the correct choice of hardness of the surface of machine parts, the effectiveness of the final result depends to a large extent - long-term performance at minimal costs. Test algorithms should form the technology in such a way as to determine what and how to apply in the technology of obtaining protective coatings. The technology should provide for a range of different modes of chemical-thermal treatment, control and diagnostic devices - from manual to automated execution with rationally connected their applications in the production, testing and operation of parts of machines. It should have a wide range of algorithms and programs that are applied to specific details, operations and tasks of increasing the wear resistance of steel parts operating under sliding friction conditions. The use of a

Corresponding author: Borys Sereda

E-mail: seredabp@ukr.net

This open access article is distributed under a Creative Commons Attribution (CC-BY) 4.0 license. 
new technology for the formation of wear-resistant coatings in conditions of self-propagating hightemperature synthesis requires thorough study and research.

Currently, the main methods of applying a protective coating are: galvanic precipitation during electrolysis, gas-thermal spraying or metallization, thermal diffusion saturation in powder, immersion in molten metal, cladding. The most advanced techniques in this area include surface hardening using laser technology, electron beams, ion implantation, etc., as well as classical methods of chemical-thermal surface treatment (nitriding, boriding). Methods of obtaining protective coatings on metal products differ in coating technology, and the main purpose of the creation is good adhesion to the substrate, as well as obtaining a continuous, non-porous and resistant to this environment protective layer. By the type of joining the protective layer with the substrate, adhesive and diffusion metallic coatings are distinguished.

Surface saturation of steel with aluminum, chromium, zinc and other elements is called diffusion saturation with metals (Trefilova, 2014; Sereda, Kalinina \& Krugliak, 2004). The product, the surface of which is enriched with these elements, acquires valuable properties, including high heat resistance, corrosion resistance, increased wear resistance and hardness.

In this regard, the actual application of technologies that allow to receive coatings with limited or minimal time of their formation. One of these technologies is the self-propagating high-temperature synthesis method (Lakhtin, 1993; Merzhanov \& Rogachev, 2003; Sereda, Kryglyak \& Sereda, 2017a; 2017b).

Many scientists are engaged in issues of increasing the wear resistance of machine parts. Recently, the use of chromo-alinated coatings has become widespread. Chromo-alimation - simultaneous or sequential saturation of metals and alloys with chromium and aluminum - is used primarily to increase wear, heat and corrosion resistance of parts (Sereda et al., 2015; 2016).

The main methods of chromium-imaging include: solid, from the vapor phase, gas and liquid. In turn, the saturation from the vapor phase is divided into contact and non-contact, gas - simultaneous and sequential, solid - simultaneous and from the slip.

Doping of chromium-plated coatings with titanium silicon and boron allows to dramatically increase performance and, along with high corrosion and heat resistance, to obtain more universal layers with high surface hardness, scale and corrosion resistance due to the formation of additional silicon and titanium oxides (Sereda et al., 2011; 2014; 2015; 2017).

The purpose of this work is the theoretical and experimental study of the physic-chemical processes underlying the production of alloyed titanium coatings on steel products, the development of technology and the optimization of the compositions of the reaction powder mixtures for titaniumsilicon-coating of parts of internal combustion engines of trucks. Analysis of the technological parameters of the SHS process. The study of the structure, phase, chemical composition of coatings. As well as studies of their wear resistance.

\section{Methodology}

The processing of carbon steel parts (steel 45, U8) was carried out in the thermal self-ignition mode using the principle of gas transport chemical reactions (Shefer, 1964; Kostogorov, 1992). The processes of titano-chromism were carried out in open-type reactors $(\mathrm{P}=105 \mathrm{~Pa})$. The working temperature range varied in the range of $850 \div 1050^{\circ} \mathrm{C}$, the maximum duration of isothermal exposure was 60 minutes.

Powders with a dispersity of 150-350 microns were used as reaction agents.

1. $\mathrm{Cr}_{2} \mathrm{O}_{3}$ - chromium (III) oxide - a source of chromium in the coating.

2. $\mathrm{Al}_{2} \mathrm{O}_{3}$ - aluminum oxide (III) - an inert additive.

3. $A l$ - aluminum grade ASD1 - oxide reducing agent, a source of aluminum in the coating.

4. $T i$ - technical grade titanium - a source of titanium in the coating.

5. $\mathrm{Cr}$ - chrome of technical purity - a source of chromium in the coating.

6. $I_{2}-$ metallic iodine - an activator of the saturation process.

7. $\mathrm{NH}_{4} \mathrm{Cl}$ - ammonium chloride - the activator of the saturation process.

The surface preparation of the samples consisted in successive grinding, polishing and degreasing in acetone. The initiation of the thermal self-ignition process was initiated by preheating in the 
resistance furnace to the temperature of the beginning of the exothermic reaction $(t *)$ (heating rate $\left.0.5^{\circ} \mathrm{C} / \mathrm{s}\right)$.

The temperature of the SHS mixtures was controlled by chromel-alumel and tungsten-rhenium thermocouples in a protective case placed in the volume of the reaction mixture, and connected to a potentiometer of the KSP series. The thickness of the hardened layers of the coatings was studied on light microscopes "Neophot-21", "Neophot-35" with an increase to $\times 250, \times 500$. The microstructure was detected by etching in a 3\% alcoholic solution of picric acid (TU 6-09-08-317-80). To identify the boundaries of ferrite grains, a 4\% alcoholic solution of nitric acid (Bekkert, 1979) was used.

For the analysis of the phase composition of the coatings, an x-ray diffractometer DRON-3M was used. The study of the elemental composition of the coatings was carried out by the method of micro Xray spectral analysis using a JEOL "Superprob-733" microanalyzer. The microhardness of the coatings was determined on a PMT-3 device with a load of $0.098 \mathrm{~N}$ and $0.196 \mathrm{~N}$. Tests for wear resistance were carried out under friction against loosely fixed particles (GOST 23.208-79) on the SMT-1 unit. (tpr. = $1050^{\circ} \mathrm{C}, \tau=60 \mathrm{~min}$.). To create an abrasive-oil environment, an abrasive material prepared from quartz sand (GOST 2138-84) was added to the oil bath of a friction machine. To calculate the equilibrium composition of the system products, the applied software packages "ASTRA.4", TERRA and Rcalcal were used (Sinjarev, Vatolin, Trusov \& Moiseev, 1982).

\section{Research results}

In the work to apply coatings, steel 50 and U8A were used. Chemical-thermal treatment was carried out in an open-type reactor $\left(\mathrm{P}=10^{5} \mathrm{~Pa}\right)$ in the temperature range $900-1050{ }^{\circ} \mathrm{C}$ and the total duration of isothermal soaking up to $60 \mathrm{~min}$.

In order to search for compositions of powder SHS mixtures providing high wear resistance, a full factor experiment

As independent variables, the following were chosen: the content in the SHS mixture of the chromium component, silicon, boron and aluminum. As the starting material, steel 50 was chosen. The process activator is $\mathrm{J}_{2}$ and $\mathrm{NH}_{4} \mathrm{~F}$ for all systems.

The calculated levels of the variation intervals, the nature of their variations and the coding schemes are presented in Tables 1 and 2 Introduction of more than $5 \%$ of the gas transport agent into the mixture leads to a strong etching of the sample surface, less than $1 \%$ does not activate the course of all gas transport reactions.

To obtain a $100 \%$ composition of powdered SHS mixtures, $\mathrm{Al}_{2} \mathrm{O}_{3}$ was used as the final product.

As a result of regression analysis, a number of equations were obtained showing the dependence of the wear resistance of protective coatings on the regime of thermal autoignition and the content of alloying elements.

To assess the adequacy of the equations, a calculation was made of the regression equations obtained for the optimum regime of thermal autoignition. The results of the calculations were compared with experimental studies. As can be seen from Table 4, the error between the calculated and experimental values of the response function does not exceed 5.

For the purpose of determining the regime and SHS-compositions ensuring the optimal indices of wear resistance of the coatings, three-dimensional graphical dependences were constructed (Fig. 1-2).

Figure 1: Optimization of the abrasion resistance of the surface layer for the Cr-Al-B system: the effect of boron and aluminum on the wear resistance of steel
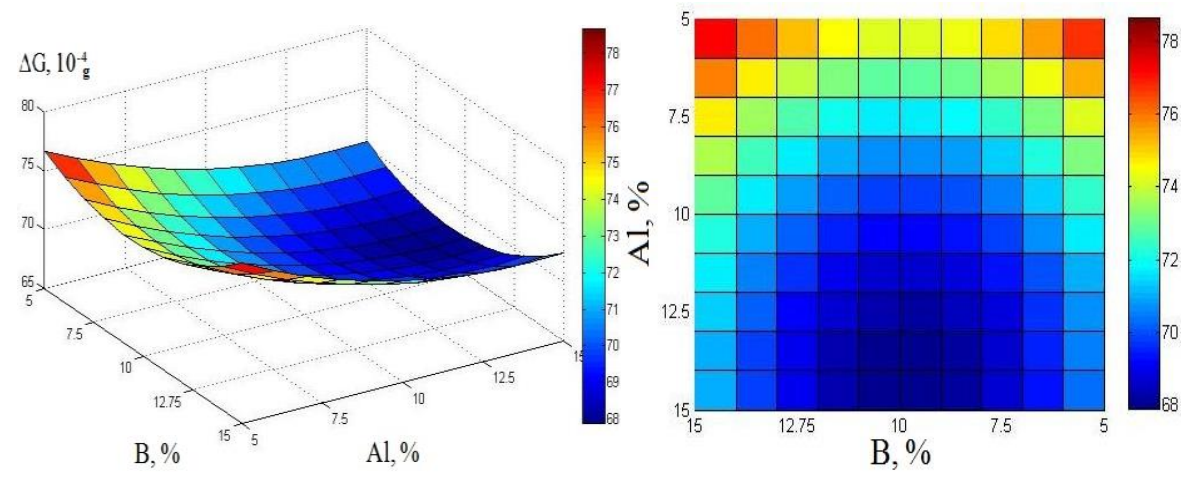
Figure 2: Optimization of the wear resistance of the surface layer for the $\mathrm{Cr}$-Al-Si system: the effect of boron and chromium content on the wear resistance of steel 50
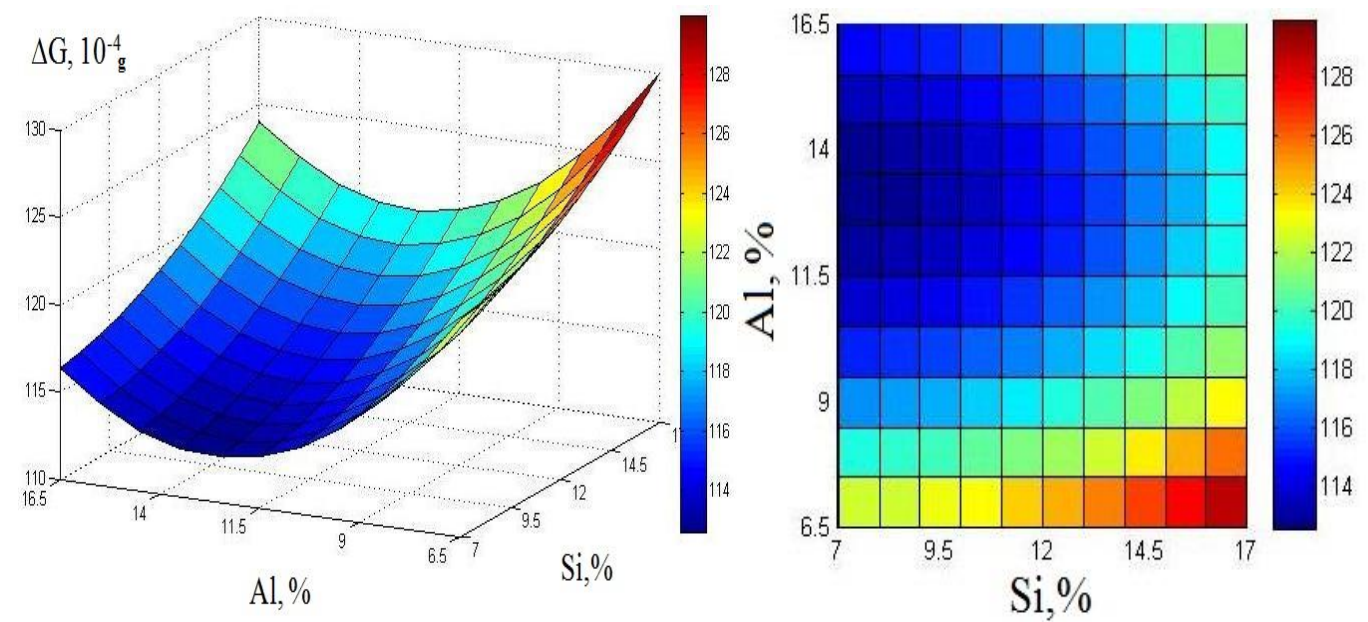

\section{Discussion of the results}

Analysis of the reactions taking place in the SHS process, as well as the results of experiments and metallographic studies, allowed to obtain a scheme for the formation of protective coatings. The process of formation of protective coatings in the regime of thermal autoignition can be conditionally divided into five stages-inert heating of the SHS mixture to the autoignition temperature, thermal autoignition, heating of the parts, isothermal aging and cooling.

Studies have shown that such a high rate of formation of coatings can be explained by the fact that austenite formed during high-temperature heating due to the autoignition stage is characterized by high structural defectiveness and fine-grained, which sharply increases its diffusion susceptibility by saturable elements. Thus, it is possible to control both the growth rate of the layers and their phase composition and structure. The main factors influencing the kinetics of the formation of protective layers are the composition of SHS-charge, the amount of chromium component, the time of isothermal aging, the composition of the processed steel, and the type of SHS process passing in combustion or in the regime of thermal autoignition.

When depositing chromium-plated silicon-doped layers on the surface, a (FeCrAl)3C layer is formed on materials with a high carbon content (steel 50, U8A), carbides (FeCr)23C6 are formed. Directly to the layer adjoins the carbon-rich transition zone formed by the counter diffusion of carbon, followed by a depleted carbon-ferrite zone.

Figure 3: Microstructures of multicomponent chromium-plated coatings obtained in the regime of thermal self-ignition of SHS, (a) - alloying Cr; (b) - alloying Al; (c) - alloying Si

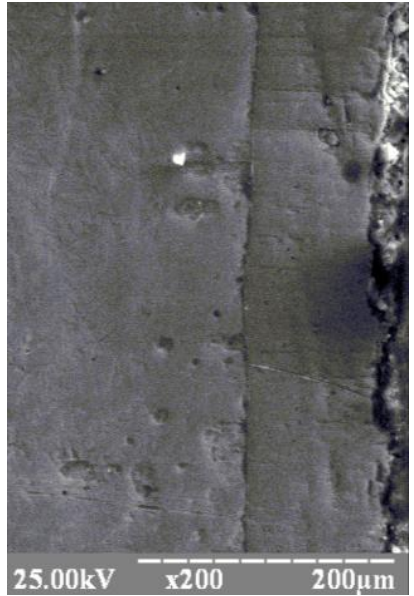

(a)

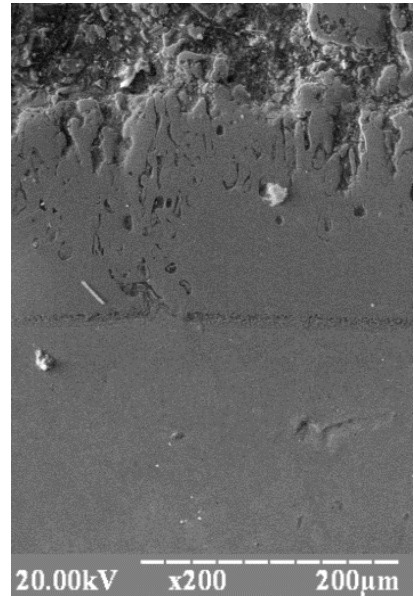

(b)

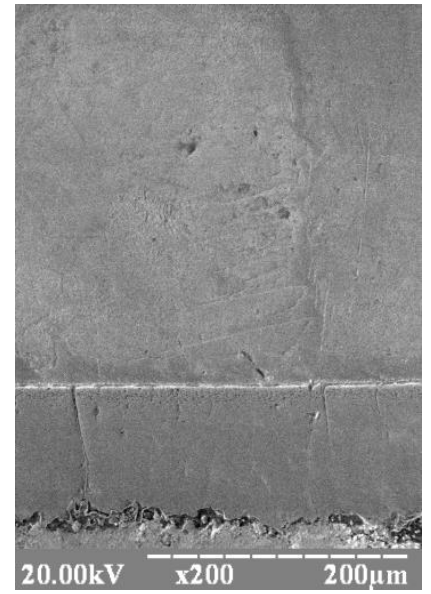

(c) 
The results of testing steel specimens for wear under conditions of sliding friction on the friction machine SMT-1 are shown in Fig. 4. Here, the wear resistance of the treated samples is 2-3 times higher than the wear resistance of the untreated samples.

The result obtained correlates with the hardness of the hardened zones. With increasing hardness, wear resistance increases. The hardness was measured on transverse sections on a PMT-3 device, using a standard procedure. As the carbon content in steels increases, the micro hardness of the surface layer increases.

\section{Figure 4: Effect of the test time on the wear resistance of coatings on steel 50 when tested on a} CMT-1 friction machine

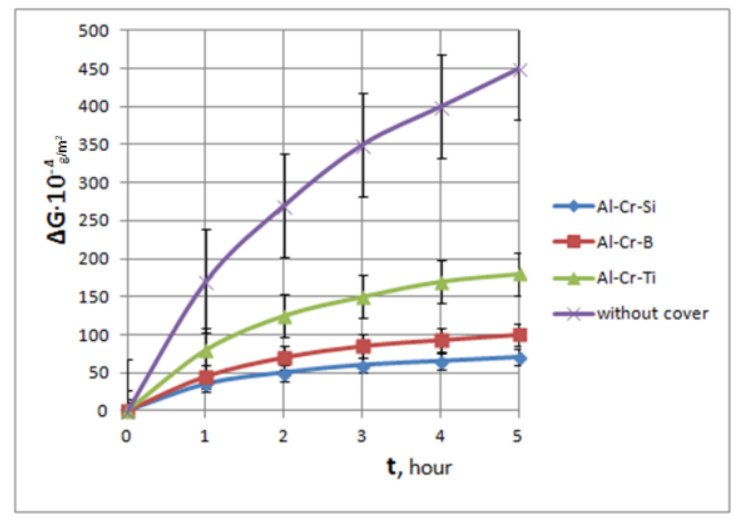

\section{Conclusions}

Modeling has been carried out to find the optimum powder SHS-mixtures for the production of wear-resistant protective coatings on steel 50 and U8A using self-propagating high-temperature synthesis technology. The structures of the protective layers and their wear resistance under conditions of sliding friction are investigated. The best wear resistance, among the coatings under consideration, are Cr-Al-B coatings. The result obtained correlates with the hardness of the hardened zones. With increasing hardness, wear resistance increases. The hardness was measured on transverse sections on a PMT-3 device, using a standard procedure. As the carbon content in steels increases, the microhardness of the surface layer increases. Their wear resistance is 4.8-5 times higher than in uncoated samples, $\mathrm{Cr}-\mathrm{Al}-\mathrm{Si}$ and $\mathrm{Cr}-\mathrm{Al}-\mathrm{Ti}$ in 2.1-3.5 times.

\section{Citation information}

Sereda, B., Kruglyak, I., Sereda, D., Gaydaenko, A., \& Kruglyak, D. (2019). Development of wearresistant coatings for automotive parts after processing in SHS conditions. Journal of Sustainable Development of Transport and Logistics, 4(1), 25-30. doi:10.14254/jsdtl.2019.4-1.3.

\section{References}

Bekkert, M. (1979). Spravochnik po metallograficheskomu travleniju [Handbook of metallographic etching]. Moscow: Metallurgija Publ.

Kostogorov, E.P. (1992). Transport reactions SHS combustion. Int. Journal of SHS, 1(1), 33-39.

Lakhtin, Yu. M. (1993). Metallurgy and thermal processing of metals. Moscow: Metallurgy.

Merzhanov, A.G., \& Rogachev, A.S. (2003). Phase and structure transformations during SHS. Adv. Sci. Techn., 31, 271-282.

Sereda, B., \& Sereda D. (2011). Kinetiks formation of aluminized multifunctional coating on steel in SHS condition. Material science and technology, 1667-1671.

Sereda, B., \& Sereda, D. (2014). Aluminized multifunctional coating on steel in SHS condition. Material science and technology, 482-486. 
Sereda, B., \& Sereda, D. (2015a). Modeling deformation in material processing and laws of phasic by SHS pressing intermetallics alloys. Material science and technology, 611-617.

Sereda, B., \& Sereda, D. (2016a). Corrosion resistance and mechanical properties zinc coating sheet steels, received in conditions of self-propagating high temperature synthesis. Material science and technology, 825-829.

Sereda, B., \& Sereda, D. (2016b). Development of protective coatings formulations based on boron for units operating at high temperatures in metallurgy. Material science and technology, 931-934.

Sereda, B., Kryglyak, I., \& Sereda, D. (2017a). Production of highly effective SHS coatings operating in oxidizing and corrosive environments. Material science and technology, 424-429.

Sereda, B., Kryglyak, I., Kovalenko, A., \& Sereda, D. (2017b). Simulation and modeling of metallurgical phenomena produced on pressing in SHS-condition. Material science and technology, 727-732.

Sereda, B., Sereda, D., \& Sereda, I. (2017c). Establishment of the relationship between the microstructure characteristics and the heat resistance of silicate coatings obtained under SHS conditions. Material science and technology, 412-416.

Sereda, B.P., Kalinina, N.E., \& Krugliak, I.V. (2004). Surface reinforcement of materials. Monograph. Zaporozhye: RVB ZDIA.

Sereda, D. (2017c). Obtaining of wear-resistant carbide coatings on high-carbon steels under SHS conditions. Material science and technology, 417-420.

Sereda, B., \& Sereda, D. (2015b). Advanced chromoaluminizing coatings for wear and heat-resistance on composite materials under SHS. Material science and technology, 229-232.

Shefer, G. (1964). Himicheskie transportnye reakcii [Chemical transport reactions]. Moscow: Mir Publ.

Sinjarev, G.B., Vatolin, N.A., Trusov, B.G., Moiseev, R.K. (1982). Primenenie JeVM dlja termodinamicheskih raschetov metallurgicheskih processov [Computer application for thermodynamic calculations of metallurgical processes]. Moscow: Nauka Publ.

Trefilova, N.V. (2014). An analysis of modern methods of application of protective coatings. Modern Science-intensive Technologies, 10, 67.

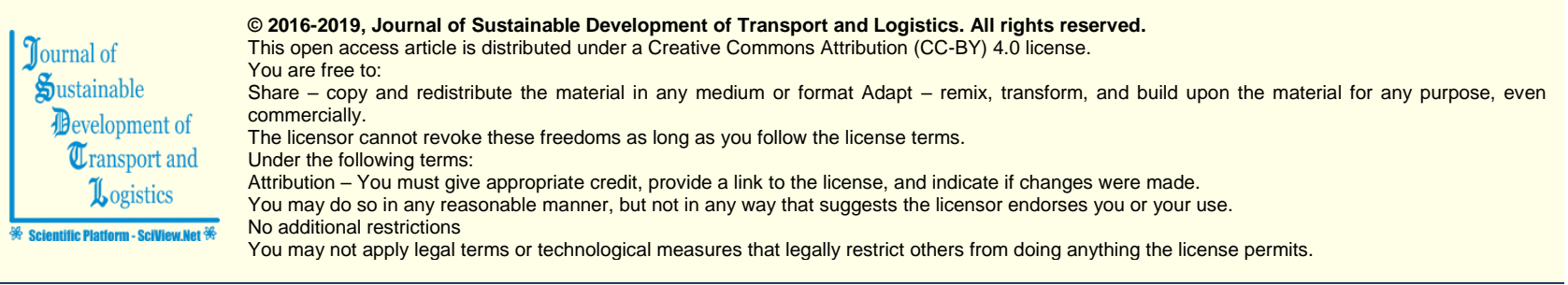

Journal of Sustainable Development of Transport and Logistics (ISSN: 2520-2979) is published by Scientific Publishing House "CSR", Poland, EU and Scientific Publishing House "SciView", Poland, EU

Publishing with JSDTL ensures:

- Immediate, universal access to your article on publication

- High visibility and discoverability via the JSDTL website

- Rapid publication

- Guaranteed legacy preservation of your article

- Discounts and waivers for authors in developing regions

Submit your manuscript to a JSDTL at https://jsdtl.sciview.net/ or submit.jsdtl@sciview.net 